\author{
Mario Francesco Fraioli \\ Riccardo Santoni \\ Chiara Fraioli \\ Filiberto Contratti
}

Received: 25 January 2005

Published online: 30 November 2005

C) Springer-Verlag 2005
Commentaries on this paper are available at http://dx.doi.org/10.1007/s00381-005-11927, http://dx.doi.org/10.1007/s00381-0051193-6, http://dx.doi.org/10.1007/s00381005-1194-5, http://dx.doi.org/10.1007/ s00381-005-1195-4, http://dx.doi.org/ 10.1007/s00381-005-1196-3 and http://dx.doi.org/10.1007/s00381-005-1197-2

M. F. Fraioli $(\bowtie) \cdot$ F. Contratti Department of Neurosciences, Neurosurgery,

Tor Vergata University of Rome,

Via Oxford 81, 00133 Rome, Italy e-mail: b.fraioli@libero.it Tel.: +39-06-20903057

Fax: +39-06-20903056

\section{"Conservative" surgical approach and early postoperative radiotherapy in a patient with a huge cystic craniopharyngioma}

\author{
R. Santoni · C. Fraioli \\ Department of Diagnostic for Imaging, \\ Intervention Radiology \\ and Radiotherapy, \\ Tor Vergata University of Rome, \\ Rome, Italy
}

\begin{abstract}
Objective: The treatment of huge craniopharyngiomas represents a therapeutic challenge for neurosurgeons. Some authors prefer to run the high risks of total removal at primary surgery, while others do not despise subtotal removal in accordance with a multidisciplinary treatment. Methods: We report the case of a 17-year-old girl who underwent subtotal removal (tumour remnant with maximum diameter of $2.5 \mathrm{~cm}$ ) of a huge cystic craniopharyngioma by frontotemporal approach, followed by early external fractionated radiotherapy by linear
\end{abstract}

accelerator. Serial magnetic resonance imaging during a follow-up period of 5 years showed a progressive marked reduction of the tumour remnant, accompanied by a complete recovery of visual deficits and an almost complete regression of diencephalic disturbances. Conclusions: Subtotal removal followed by early fractionated radiotherapy can be an effective treatment for huge craniopharyngiomas. Such a multidisciplinary treatment may favour tumour control and assure a satisfactory quality of life as well.

Keywords "Giant" cystic craniopharyngioma - "Conservative" surgical approach - Postoperative external radiotherapy ·

Endocrinological and visual deficits

\section{Introduction}

The treatment of huge craniopharyngiomas, with a diameter of $4 \mathrm{~cm}$ or more [21], represents a therapeutic challenge for the neurosurgeon. Some authors are in favour of a radical tumour removal at the primary surgery $[13,15,18$, 21]; others suggest subtotal or partial tumour excision followed or not by radiotherapy $[2,6-10,17,20]$, especially in cases involving the hypothalamic structures on preoperative neuroimaging studies. Multidisciplinary treatment in case of partial tumour removal includes also postoperative brachytherapy $[1,3,16,19]$ and topic antiblastic therapy $[4,14]$.
We present a case of a 17-year-old girl who underwent transcranial subtotal removal of a huge predominantly cystic craniopharyngioma followed by early postoperative external fractionated radiotherapy by linear accelerator (LINAC). Serial magnetic resonance imaging (MRI) studies allowed to evaluate the clinical results of such a combined management as well as the behaviour of the residual tumour.

\section{Materials and methods}

A 17-year-old girl suffered from oligomenorrhoea and obesity during the last 3 years prior to admission. Since 1 
Fig. 1 Preoperative post-contrast MRI of the voluminous supradiaphragmatic craniopharyngioma (maximum diameter $6 \mathrm{~cm}$ ) in sagittal (a) and coronal (b) slices. Two "ring enhancement" of two hypointense cystic formations, left $>$ right, are evident. There is no enlargement of the turcic sella (white arrow)
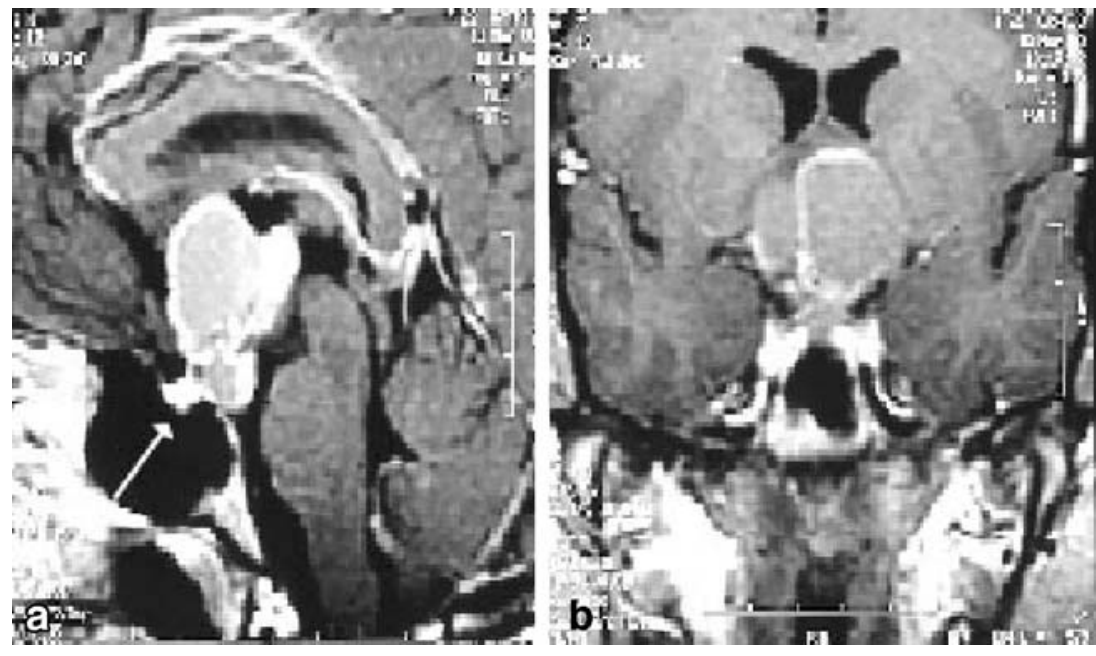

year, diabetes insipidus had also appeared. A marked bilateral decrease in visual acuity and a reduction of the visual field were noted in the last month before diagnosis.

At admission, the ophthalmological examination revealed a visual acuity impairment [1/10 left eye (LE) and $5 / 10$ right eye (RE)] and bitemporal hemianopsia prevalent in the median-upper quadrants, left $>$ right. Body weight was $90 \mathrm{~kg}$ and height was $164 \mathrm{~cm}$ [body mass index (BMI) $33 \mathrm{~kg} / \mathrm{m}^{2}$ ]. Hormonal study revealed a marked panhypopituitarism, with moderate increase in prolactin secretion (65 ng/ml).

The MRI studies showed a bilateral suprasellar mass, with a maximum diameter of $6 \mathrm{~cm}$, extending behind the sella turcica, into the cisterna interpeduncularis, and in the upward direction close to the foramina of Monro. After administration of contrast medium, two "ring enhance- ment" of two main cystic formations, left>right, were evident (Fig. 1).

\section{Surgical treatment}

Through a non-dominant right frontotemporal approach, a microsurgical partial removal of the solid component and a subtotal excision of the cystic components were performed. The cystic membranes were tenaciously adhering to the optic chiasma, to the pituitary stalk and to the diencephalic structures. A tumour remnant with a maximum diameter of $2.5 \mathrm{~cm}$ was evident at the postoperative MRI carried out 9 days after the operation (Fig. 2).

At the discharge, 10 days after the surgical operation, the visual acuity and visual field had improved; in particular, the visual acuity was $5 / 10$ on LE and $7 / 10$ on RE. The
Fig. 2 Postoperative post-contrast MRI in sagittal (a) and coronal (b) slices, performed 9 days after the operation. A tumour remnant with a maximum diameter of $2.5 \mathrm{~cm}$ is evident (white arrows)
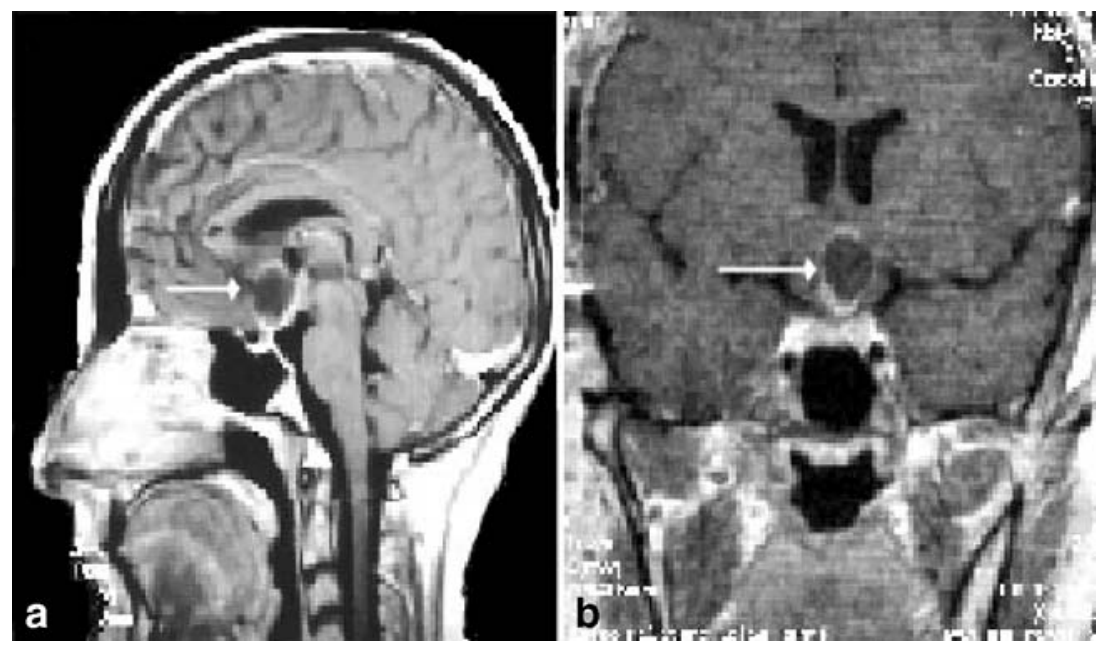
Fig. 3 Post-contrast MRI, performed 1 year after the end of radiotherapy, in sagittal (a) and coronal (b) slices. A reduction of the tumour remnant is evident (white arrows)
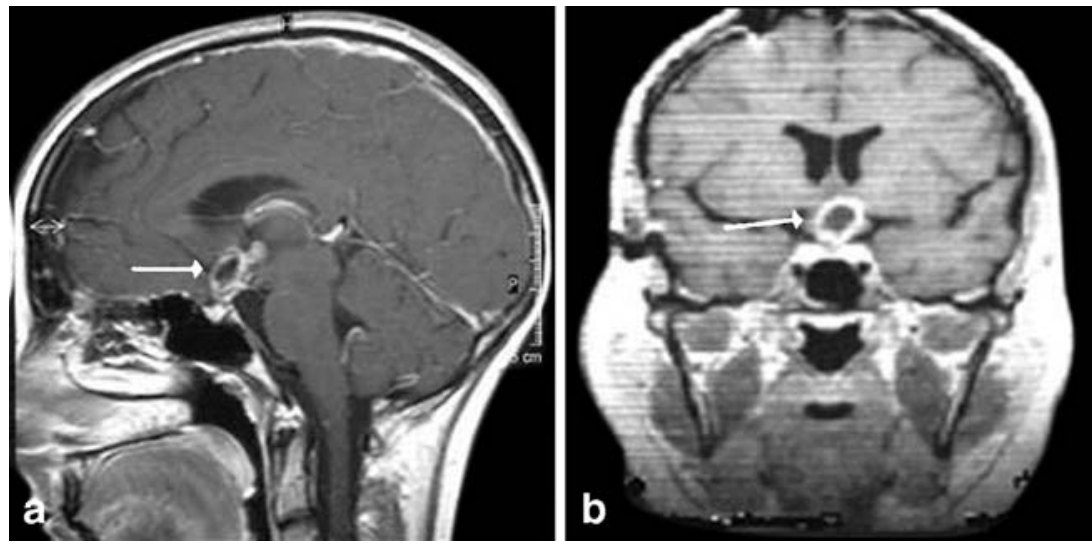

diabetes insipidus had become well controlled by vasopressin administered nasally. No significant changes in the hormonal status as compared with the preoperative phase were apparent. The patient was discharged in good general condition and under appropriate hormonal substitute treatment.

\section{Radiotherapeutic treatment}

Nine days after discharge, conventional radiotherapeutic treatment was started by LINAC using a three-field technique $\left(0,90\right.$ and $\left.270^{\circ}\right)$; a total dose of 60 Gy (International Commission of Radiological Units point) was delivered to the target in 30 fractions.

Steroids were given during all courses of radiotherapy. Blood hormonal levels during and after treatment were normal. Hormonal tests carried out 2 months after the end of treatment showed that hypopituitarism was stationary.

\section{Observations and results}

Three months after the completion of radiotherapy, the patient was in excellent general condition. The visual acuity and visual field defects were within the normal limits. The diabetes insipidus persisted, but it was easily controlled with medications (one application of rhinal spray desmopressin in the morning and one in the evening). Hypopituitarism was not significantly modified. Obesity was unchanged in comparison to the preoperative status.

One year after the end of radiotherapy, the MRI showed an evident reduction in size of the tumour remnant (Fig. 3). The patient had lost $10 \mathrm{~kg}$ in body weight (BMI $29.74 \mathrm{~kg} /$ $\mathrm{m}^{2}$ ), and the endocrine disorders were better controlled with medications.

Two and a half years after the end of radiotherapy, a further reduction of the residual tumour was evident at MRI: the cystic component was absent (Fig. 4). The patient had lost further $10 \mathrm{~kg}$ in weight (BMI $26 \mathrm{~kg} / \mathrm{m}^{2}$ ).
Fig. 4 Post-contrast MRI, performed 2.5 years after the end of radiotherapy, in sagittal (a) and coronal (b) slices. A further reduction of the residual tumour is evident: the cystic component is absent (white arrows)

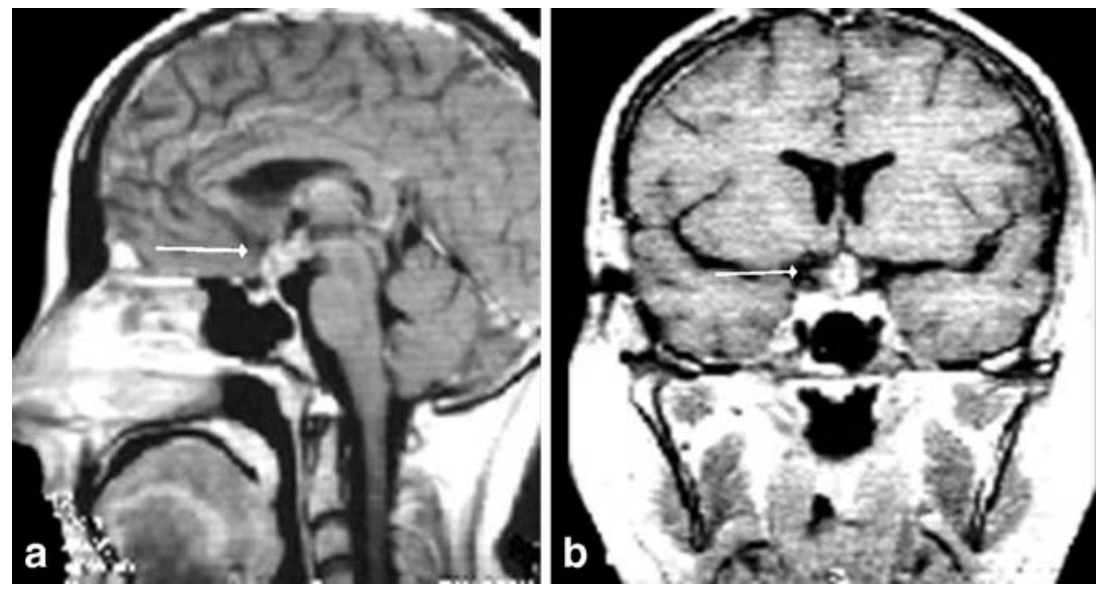


Fig. 5 Post-contrast MRI, performed 4 years after the end of radiotherapy, in sagittal (a) and coronal (b) slices. A slight reduction of the solid tumour remnant is evident (white arrows)
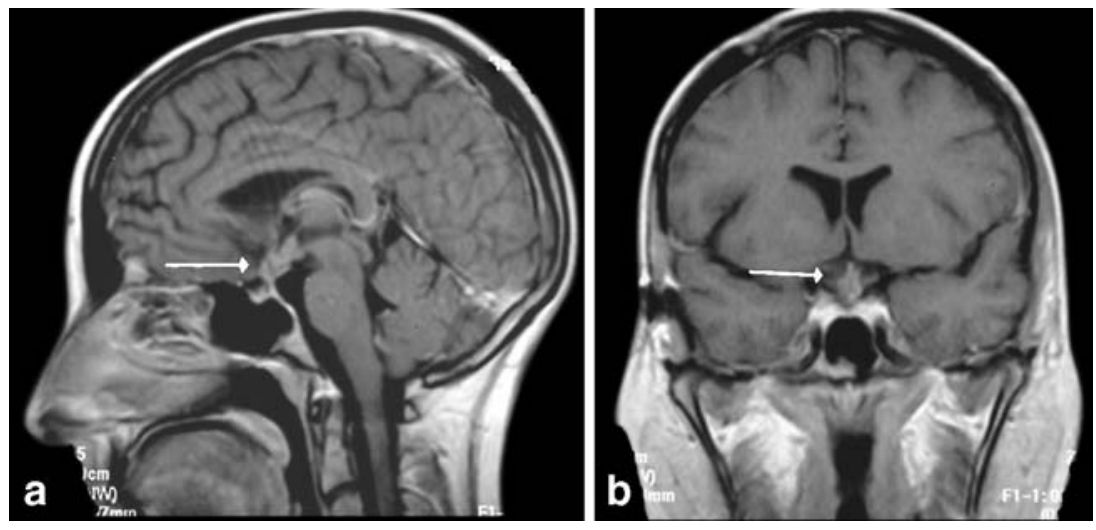

Hypopituitarism required low doses of substituted hormones. The amount of vasopressin required to control the diabetes insipidus was also reduced (one single application of rhinal spray desmopressin).

An MRI obtained 4 years after the end of radiotherapy demonstrated a further slight reduction of the solid tumour remnant (Fig. 5). The patient was in excellent general condition, and she had lost $20 \mathrm{~kg}$ of weight since operation (BMI $26 \mathrm{~kg} / \mathrm{m}^{2}$ ). She was no longer dependent on hormonal substitution 5 years after the completion of the radiotherapeutic treatment, except for dysmenorrhoea and diabetes insipidus.

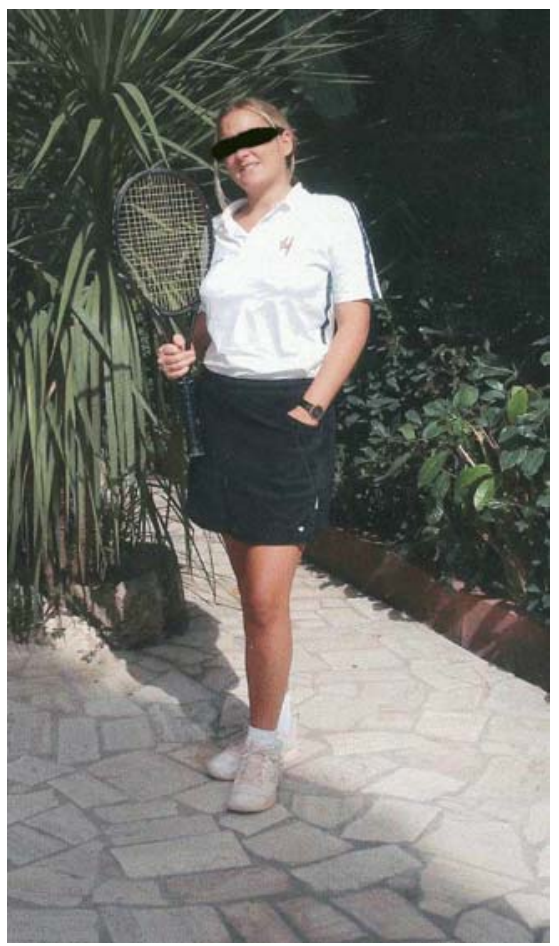

Fig. 6 The patient, 5 years after the completion of the multimodality treatment
At present, the radiological and clinical conditions are stationary. The patient is a healthy girl who works as a tennis instructor in a sporting club (Fig. 6).

\section{Discussion and conclusions}

Surgical strategies of craniopharyngiomas are a controversially discussed argument. Especially in case of large tumours, the complete excision might be associated with a high mortality [21]. In long-term survivors, the quality of postoperative life after radical removal is unsatisfactory in many cases [8-12]. A further argument against total surgical tumour excision associated with high mortality and morbidity is that the "total" surgical removal does not prevent the possibility of local relapse [5-7], even in patients without any residual tumour on postoperative MRI. Accordingly, some neurosurgeons [2, 7-9, 12, 20] suggest subtotal or partial tumour removal as the best therapeutic option, at least in cases of huge craniopharyngiomas. Limited surgery aims at reducing the risk of mortality and the severity of the postoperative complications. In case of subtotal or partial tumoural excision, several authors recommended conventional postoperative radiotherapy on the tumour remnants $[2,7-9]$. In patients with residual cystic component, the direct or stereotaxic aspiration of the liquid content of tumour cyst, possibly associated with intracavitary brachytherapy $[3,16,19]$ or bleomycin instillation [4, 14], was the more commonly adopted associated therapeutic manoeuvre.

The main limit of these therapeutic tools is their potentially harmful effect on the optic pathways and the pituitary-diencephalic structures. However, nowadays, such complications are significantly reduced due to new and improved modalities of radiation administration.

Our reported case indicates that excellent results may be achieved by the combination of partial tumour removal and radiotherapy, as demonstrated by the progressive complete recovery of visual deficits and by the marked regression of the pituitary-diencepalic dysfunction, which took place 
during and after the radiotherapeutic treatment as well as by the progressive reduction in size of the tumour remnant.

In conclusion, it should be discussed whether a strategy of subtotal removal and postoperative radiotherapy of craniopharyngioma should be adopted as first-line treatment in difficult cases, namely, in patients with preoperative hypothalamic involvement. Such a deliberate policy is obviously in contrast to the frequently chosen strategy of "radical" tumour removal, followed by radiotherapy.

Based on our reported case, we speculate that in patients with large tumours extending to suprasellar areas, limited surgical strategies followed by external fractionated irradiation might have more beneficial effects on long-term prognosis than radical surgical approaches.

\section{References}

1. Backlund EO (1994) Treatment of craniopharyngiomas: the multimodality approach. Pediatr Neurosurg 21 (Suppl 1):82-89

2. Baskin DS, Wilson CB (1986) Surgical management of craniopharyngiomas: a review of 74 cases. J Neurosurg 65:22-27

3. Blackburn TP, Doughty D, Plowman PN (1999) Stereotactic intracavitary therapy of recurrent cystic craniopharyngioma by instillation of 90yttrium. Br J Neurosurg 13(4):359-365

4. Broggi G, Giorgi C, Franzini A (1989) Preliminary results of intracavitary treatment of craniopharyngiomas with bleomycin. J Neurosurg Sci 33 (1):145-148

5. Caldarelli M, Di Rocco C, Papacci F, Colosimo C Jr (1998) Management of recurrent craniopharyngioma. Acta Neurochir (Wien) 140:447-454

6. Carmel PW, Antunes JL, Chany CH (1982) Craniopharyngiomas in children. Neurosurgery 11:382-389

7. Falhbush R, Honegger J et al (1999) Surgical treatment of craniopharyngiomas: experience with 168 patients. J Neurosurg 90:237-250
8. Fischer EG, Welch K, Shillito J Jr, Winston KR, Tarbell NJ (1990) Craniopharyngiomas in children. Longterm effects of conservative surgical procedures combined with radiation therapy. J Neurosurg 73(4):534-540

9. Guidetti B, Fraioli B (1979) Craniopharyngiomas. Results of surgical treatment. Acta Neurochir Suppl (Wien) 28(2):349-351

10. Katz EL (1975) Late results of radical excision of craniopharyngiomas in children. J Neurosurg 42(1):86-93

11. Landolt AM, Zachmann M (1991) Results of transsphenoidal extirpation of craniopharyngiomas and Rathke's cysts. Neurosurgery 28:410-415

12. Lunsford LD, Pollock BE, Kondziolka DS et al (1994) Stereotactic options in the management of craniopharyngioma. Pediatr Neurosurg 21(Suppl 1):90-97

13. Maira G, Anile C, Albanese A, Cabezas D, Pardi F, Vignati A (2004) The role of transsphenoidal surgery in the treatment of craniopharyngiomas. J Neurosurg 100(3):445-451

14. Mottolese C, Stan H, Hermier M, Berlier P, Convert J, Frappaz D, Lapras C (2001) Intracystic chemotherapy with bleomycin in the treatment of craniopharyngiomas. Childs Nerv Syst 17(12):724-730
15. Samii M, Bini W (1991) Surgical treatment of craniopharyngiomas. Zentralbl Neurochir 52:17-23

16. Shapiro B, Fig LM, Gross MD (1999) Intracavitary therapy of craniopharyngiomas. Q J Nucl Med 43(4):367-374

17. Sweet WH (1980) Recurrent craniopharyngiomas. Therapeutic alternatives. Clin Neurosurg 27:206-229

18. Symon L, Pell MF, Habib AH (1991) Radical excision of craniopharyngioma by the temporal route: a review of 50 patients. Br J Neurosurg 5(6):539-549

19. Van den Berge JH, Blaauw G, Breeman WAP et al (1992) Intracavitary brachytherapy of cystic craniopharyngiomas. J Neurosurg 77:545-550

20. Van Effenterre R, Bosch AL (2002) Craniopharyngioma in adults and children: a study of 122 surgical cases. J Neurosurg 97(1):3-11

21. Yasargil MG, Curcic M, Kis M et al (1990) Total removal of craniopharyngiomas. Approaches and long-term results in 144 patients. J Neurosurg $73: 3-11$ 